\title{
Agronomic efficiency and profitability of cotton on integrated use of phosphorus and plant microbes
}

\author{
H. Alia (D) and M. I. Ahmad ${ }^{a *}$ (ID)

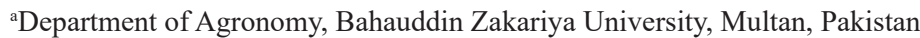 \\ *e-mail: Iftikhar.a.maher@gmail.com
}

Received: January 13, 2020 - Accepted: April 21, 2020 - Distributed: May 31, 2021

(With 2 figures)

\begin{abstract}
Cotton crop, plays a significant role in Pakistan's economy by ruling a prominent place in edible oil and local textile industry. Phosphorus (P) inaccessibility and deficiency of soil organic matter are the key restraints for low crop productivity in cotton. Therefore, a two years field study was designed during 2014-15, to explore the influence of phosphate solubilizing bacteria (PSB), farmyard manure (FYM), poultry manure (PM) and inanimate sources of $\mathrm{P}$ on various physiological, growth, yield and quality parameters of cotton crop at CCRI Multan. Field responses of seeds inoculated with two distinctive phosphate solubilizing bacteria (PSB) strains viz. $\mathrm{S}_{0}=$ control, $\mathrm{S}_{1}=$ strain-1, $\mathrm{S}_{2}=$ strain-2 and eight organic, inorganic $\mathrm{P}$ sources viz., $\mathrm{P}_{0}=$ control, $\mathrm{P}_{1}=80 \mathrm{~kg} \mathrm{ha}^{-1} \mathrm{P}$ from inorganic source, $\mathrm{P}_{2}=80 \mathrm{~kg} \mathrm{ha}^{-1} \mathrm{P}$ from FYM, $\mathrm{P}_{3}=80 \mathrm{~kg} \mathrm{ha}^{-1} \mathrm{P}$ from PM, $\mathrm{P}_{4}=40 \mathrm{~kg} \mathrm{ha}^{-1} \mathrm{P}$ from FYM $+40 \mathrm{~kg} \mathrm{ha}^{-1} \mathrm{P}$ from inorganic source, $\mathrm{P}_{5}=40 \mathrm{~kg} \mathrm{ha}^{-1} \mathrm{P}$ from $\mathrm{PM}+40 \mathrm{~kg} \mathrm{ha}^{-1} \mathrm{P}$ from inorganic source, $\mathrm{P}_{6}=80 \mathrm{~kg} \mathrm{ha}^{-1} \mathrm{P}$ from FYM $+40 \mathrm{~kg} \mathrm{ha} \mathrm{F}^{-1} \mathrm{P}$ from inorganic source, $\mathrm{P}_{7}=80 \mathrm{~kg} \mathrm{ha}^{-1} \mathrm{P}$ from $\mathrm{PM}+40 \mathrm{~kg} \mathrm{ha}^{-1} \mathrm{P}$ from inorganic source and $\mathrm{P}_{8}=40 \mathrm{~kg}^{-1} \mathrm{P}$ from $\mathrm{FYM}+40 \mathrm{~kg} \mathrm{ha}^{-1} \mathrm{P}$ from PM were evaluated. Results revealed that inoculation of seeds with PSB and collective use of inorganic and organic sources of $\mathrm{P}$ had considerably increased the yield contributing attributes in cotton. However, the treatment $\mathrm{P}_{7}\left(80 \mathrm{~kg} \mathrm{P} \mathrm{ha}^{-1}\right.$ from $\mathrm{PM}+40 \mathrm{~kg} \mathrm{P} \mathrm{ha}^{-1}$ from inorganic source $)$ in coincidence with seeds inoculated with PSB $\left(\mathrm{S}_{1}\right)$ produced taller plant, maximum boll weight, significantly higher LAI and CGR. Significantly higher seed cotton yield, lint yield, fiber length and maximum BCR of 1.95 and 1.81 was also obtained from the $\mathrm{P}_{7}$ treatment during both crop-growing seasons. In conclusion, combined use of $80 \mathrm{~kg} \mathrm{P} \mathrm{ha}^{-1}$ from $\mathrm{PM}+40 \mathrm{~kg} \mathrm{P}^{-1}$ from inorganic source and cotton seeds inoculated with strain-1 improved phosphorus uptake ensuing in greater consumption of photo-assimilates for maximum growth and yield.
\end{abstract}

Keywords: seed cotton, poultry manure, farmyard manure, phosphate solubilizing bacteria, fiber quality.

\section{Eficiência e rentabilidade agronômica do algodão no uso integrado de fósforo e micróbios vegetais}

\begin{abstract}
Resumo
A safra de algodão, desempenha um papel significativo na economia do Paquistão, ao ocupar um lugar de destaque no óleo comestível e na indústria têxtil local. A inacessibilidade e a deficiência de fósforo $(\mathrm{P})$ da matéria orgânica do solo são as principais restrições para a baixa produtividade das culturas em algodão. Portanto, um estudo de campo de dois anos foi desenvolvido durante 2014-15, para explorar a influência de bactérias solubilizantes de fosfato (PSB), esterco de capoeira (FYM), esterco de aves (PM) e fontes inanimadas de P sobre vários fatores fisiológicos, crescimento, rendimento e parâmetros de qualidade da cultura do algodão no CCRI Multan. Respostas de campo de sementes inoculadas com duas cepas distintas de bactérias solubilizantes de fosfato (PSB) viz. S0 = controle, S1 = cepa-1, S2 = cepa-2 e oito fontes orgânicas de P inorgânicas viz., P0 = controle, $\mathrm{P} 1=80 \mathrm{~kg}$ ha-1 P de fonte inorgânica, P2 = $80 \mathrm{~kg}$ ha- 1 P de FYM, P3 = $80 \mathrm{~kg}$ ha-1 P de PM, P4 = $40 \mathrm{~kg}$ ha-1 P de FYM + $40 \mathrm{~kg}$ ha-1 P de fonte inorgânica, P5 = $40 \mathrm{~kg}$ ha-1 P de PM $+40 \mathrm{~kg}$ ha-1 P de fonte inorgânica, P6 = 80 kg ha-1 P de FYM + 40 kg ha-1 P de fonte inorgânica, P7 = 80 kg ha-1 P de PM + 40 kg ha-1 P de fonte inorgânica e P8 = 40 Foram avaliados kg ha-1 P da FYM $+40 \mathrm{~kg}$ ha-1 P da PM. Os resultados revelaram que a inoculação de sementes com PSB e o uso coletivo de fontes inorgânicas e orgânicas de P aumentaram consideravelmente os atributos que contribuem para a produtividade no algodão. No entanto, o tratamento P7 (80 kg P ha- 1 da PM + 40 kg P ha-1 da fonte inorgânica) em coincidência com sementes inoculadas com PSB (S1) produziu planta mais alta, peso máximo de cápsula, IAF e CGR significativamente maiores. Produtividade significativamente maior do algodão, rendimento de fiapos, comprimento da fibra e BCR máximo de 1,95 e 1,81 também foi obtida a partir do tratamento P7 durante as duas épocas de cultivo. Em conclusão, o uso combinado de $80 \mathrm{~kg}$ P ha-1 de PM + $40 \mathrm{~kg}$ P ha-1 de fonte inorgânica e sementes de algodão inoculadas com a cepa-1 melhoraram a captação de fósforo, resultando em maior consumo de foto assimilados para obter crescimento e produtividade máximos.
\end{abstract}

Palavras-chave: algodão de semente, estrume de aves, estrume de quintal, bactérias solubilizantes de fosfato, qualidade da fibra. 


\section{Introduction}

Cotton (Gossypium hirsutum L.), the fiber plant is a principal cash crop, sown for both agricultural and industrial purposes in the tropical and temperate zones of the biosphere (Singh, 2004). It is predominantly used for lint production and its strength and potential to be adorned make it vital for textile stuffs (Jones and Kersey, 2002). Furthermore, it is the second most imperative source of edible oil in the world and major in Pakistan (Zhang, 2001). Cotton is the key source of employment for millions involved in production; processing, ginning, fabric industry and trade associated activities and contributes $60 \%$ of the foreign exchange earnings (Noreen et al., 2013). It contributes $0.8 \%$ share in gross domestic product and about $4.5 \%$ in agriculture value added products (Pakistan, 2018). It was grown on an area of 2.373 million hectares and produced 9.861 million bales with average production of $707 \mathrm{~kg}$ per hectare during 2018-19 (Pakistan, 2018). Pakistan being world's fourth largest fiber producer and third largest exporter of raw yarn and second prominent exporter of fiber in the world, per acre produce of cotton ranks thirteen in the world (Shuli et al., 2018). There is a huge gap between potential and the actual productivity of cotton. This gap is primarily due to cotton leaf curl virus diseases, severe insect pest attack, weeds invasion, atmospheric stresses such as high temperature and moisture stress during critical stages, less availability of quality of the seed, inappropriate planting techniques and ineffective managerial practices and limited supply of essential nutrients (Shuli et al., 2018; Arif et al., 2019).

Phosphorus is an essential element in nucleic acid and constituents of phospholipids in bio-membrane. It is also crucial for cellular energy transfer by means of protein phosphorylation and dephosphorylation, $\mathrm{Pi}$ is a basic regulator of signal transduction (Wu et al., 2005). Phosphorus scarcity adversely influences the nucleic acid, cellular membrane, leaf expansion, biosynthesis of photosynthetic pigments, dry matter production and other metabolic enzymes that finally declined the crop production up to $10-15 \%$ (Vance et al., 2003). Phosphorus is also a limited and non-renewable resource; existing assessments propose that economic supply of $\mathrm{P}$ may be rigorously exhausted over the next 300 years (Cordell and White, 2011). Improvement of $P$ acquirement efficacy by mobilizing the residual soil $\mathrm{P}$, as well as increasing the roots absorbing surface and acquisition ability for soil applied $\mathrm{P}$ to the plants is imperative for its sustainable management (Shen et al., 2013).

Collective use of organic and inorganic P sources is being considered the best way for increasing its accessibility to the cotton plants (Wang et al., 2008). The synergetic influence of organic with inorganic fertilizers improved the water holding capacity of soil, cation exchange capacity, soil aeration, phosphorus use efficiency (PUE) of applied fertilizer, soil nutrients availability, seed germination and plant growth rate which ultimately boosted up the final yield (Amanullah and Stewart, 2015). Furthermore, use of beneficial microbes (biofertilizers) such as phosphate solubilizing bacteria (PSB) as a seed inoculant, is competent of involvement in rhizosphere with agricultural crops can stimulate P accessibility to plants (Nico et al., 2012). As the beneficial microorganisms produce the organic acids which reduce the soil $\mathrm{pH}$ and improve the release of bounded $\mathrm{P}$ forms in the soil (Walpola and Yoon, 2012). PSB is not only vital for the reduction of the quantity of inorganic fertilizers and eco-friendly but also improves the crop efficiency (Yasmin and Bano, 2011).

However, the earlier studies conducted use both organic and chemical sources of P or PSB. Whereas collective usage of organic and chemical sources of P with PSB are rarely reported. It is hypothesized that collective use of organic and inorganic sources of phosphorus and seed inoculation with PSB would improve the growth attributes, yield and net returns from the cotton crop. Therefore, the existing research was planned keeping in view the objective to evaluate the role of PSB in enhancing the P uptake and increasing the productivity of cotton by exploiting distinctive sources of phosphorus.

\section{Material and Methods}

A field investigation was designed to assess the influence of $\mathrm{P}$ managing tactics on the growth, yield and fiber quality parameters of transgenic cotton at Central Cotton Research Institute (CCRI), Multan during 2014 and 2015. The experimental soil was silt loam having $\mathrm{pH} 8.0$ and 8.09, organic matter $0.83 \%$ and $0.81 \%$, EC $2.61 \mathrm{dS} \mathrm{m} \mathrm{m}^{-1}$ and $2.70 \mathrm{dS} \mathrm{m}^{-1}$, total nitrogen $0.055 \%$ and $0.045 \%$, available P 13.00 ppm and 11.60 ppm and available K 120.0 ppm and $112.0 \mathrm{ppm}$. Randomized Complete Block Design with factorial arrangement was used as experimental design and was repeated thrice. Experimental treatments comprised of two strains of PSM viz. $\mathrm{S}_{0}=$ control, $\mathrm{S}_{1}=$ strain-1, $\mathrm{S}_{2}=$ strain-2 and eight organic, inorganic $\mathrm{P}$ sources viz. $\mathrm{P}_{0}=$ control, $\mathrm{P}_{1}=80 \mathrm{~kg} \mathrm{ha}^{-1} \mathrm{P}$ from inorganic source, $\mathrm{P}_{2}=80 \mathrm{~kg} \mathrm{ha}^{-1} \mathrm{P}$ from FYM, $\mathrm{P}_{3}=80 \mathrm{~kg} \mathrm{ha}^{-1} \mathrm{P}$ from PM, $\mathrm{P}_{4}=40 \mathrm{~kg} \mathrm{ha}^{-1} \mathrm{P}$ from FYM $+40 \mathrm{~kg} \mathrm{ha}^{-1} \mathrm{P}$ from inorganic source, $\mathrm{P}_{5}=40 \mathrm{~kg} \mathrm{ha}^{-1} \mathrm{P}$ from $\mathrm{PM}+40 \mathrm{~kg} \mathrm{ha}^{-1} \mathrm{P}$ from inorganic source, $\mathrm{P}_{6}=80 \mathrm{~kg} \mathrm{ha}^{-1} \mathrm{P}$ from FYM $+40 \mathrm{~kg} \mathrm{ha}^{-1} \mathrm{P}$ from inorganic source, $\mathrm{P}_{7}=80 \mathrm{~kg} \mathrm{ha}^{-1} \mathrm{P}$ from $\mathrm{PM}+40 \mathrm{~kg}$ ha $^{-1} \mathrm{P}$ from inorganic source and $\mathrm{P}_{8}=40 \mathrm{~kg} \mathrm{ha}^{-1} \mathrm{P}$ from $\mathrm{FYM}+40 \mathrm{~kg} \mathrm{ha}^{-1} \mathrm{P}$ from PM.

A well-pulverized seedbed was made by cultivating the experimental soil three times. Beds and furrows were made with specific bed shaper and seeds of cotton cultivar CIM 602 manually dibbled. For optimum plant population, gap filling and thinning was practiced on $18^{\text {th }}$ and $32^{\text {nd }}$ days after sowing, respectively. Nitrogen fertilizer at $145 \mathrm{~kg} \mathrm{ha}^{-1}$ was dispersed at 3 stages i.e. first at sowing time, second at the start of blooming and last at peak flowering stage. Potassium fertilizer was applied at $62 \mathrm{~kg} \mathrm{ha}^{-1}$ at sowing time. Pre-emergence herbicide was applied along with four inter cultivations at 25, 40, 55 and 70 DAS to control weeds. Insect pests were controlled with spray assessments based on pest scouting. All other agronomic 
practices except fertilizer treatments were kept common for all experimental units. The crop was harvested when the cotton bolls were about $60 \%$ opened and growth and yield contributing traits data was documented by adopting prevailing techniques.

\subsection{Observations}

At the start of blooming, 10 randomly selected plants were tagged to measure the final plant height, sympodial branches, bolls plant ${ }^{-1}$ and mean boll weight. Manual harvesting of cotton was done twice from the central two rows of all experimental units to observe the seed cotton and lint yield per unit area during both growing seasons. Leaf Area Index (LAI) was computed by following the method used by Watson (1952).

\section{Equation 1. $L A I=($ leaf area $/$ land area $)$}

Crop Growth Rate (CGR) was determined by adopting the procedure followed by Hunt (1978).

Equation 2. $C G R\left(\mathrm{~g} \mathrm{~m}^{-2} d a y^{-1}\right)=\left(W_{2}-W_{1}\right) /\left(T_{2}-T_{1}\right)$

where $\mathrm{W}_{1}$ and $\mathrm{W}_{2}$ are the total dry weights harvested at times $T_{1}$ and $T_{2}$, respectively.

Net Assimilation Rate (NAR) was also assessed by using the procedure advised by Hunt (1978).

Equation 3. NAR $\left(\mathrm{g} \mathrm{m}^{-2}\right.$ day $\left.{ }^{-1}\right)=$ Total dry matter / leaf area duration

Fiber quality parameters were determined according to procedure proposed by Sundaram et al. (2002).

Collected data regarding various parameters was statistically analyzed by employing computer based software M STAT- C. Differences among treatments means were compared at probability level of $5 \%$ by using DMR test (Steel et al., 1997).

\section{Results}

Data concerning leaf area index (LAI) noted at various growth stages varied significantly due to interactive impact of PSB strains and distinctive P sources during both years (Figure 1a). Cotton seeds inoculated with strain-1 of PSB produced significantly higher LAI with the integrated use of $80 \mathrm{~kg} \mathrm{ha}^{-1} \mathrm{P}$ from PM $+40 \mathrm{~kg} \mathrm{ha}^{-1} \mathrm{P}$ from chemical source in 2014 and 2015.

Significant differences were recorded about crop growth rate (CGR) data at various growth phases of crop during both growing seasons (Figure 1b). Almost similar data trends were observed for CGR as cotton seeds inoculated with strain-1 of PSB produced significantly higher CGR with the integrated use of $80 \mathrm{~kg} \mathrm{ha}^{-1} \mathrm{P}$ from $\mathrm{PM}+40 \mathrm{~kg} \mathrm{ha}^{-1} \mathrm{P}$ from inorganic source during both study years.

Net assimilation rate (NAR) data was documented at distinctive crop stages varied significantly (Figure 1c). Integrated use of $80 \mathrm{~kg} \mathrm{ha}^{-1} \mathrm{P}$ from PM $+40 \mathrm{~kg} \mathrm{ha}^{-1} \mathrm{P}$ from inorganic source in cotton field inoculated with both strains of PSB produced higher effects regarding NAR during both years.

The use of PSB strains and distinctive sources of P was noticed to affect plant height data significantly during both growing seasons (Figure 2a). Cotton seeds inoculated with strain-1 produced significantly taller plants with the application of $80 \mathrm{~kg} \mathrm{ha}^{-1} \mathrm{P}$ from $\mathrm{PM}+40 \mathrm{~kg} \mathrm{ha}^{-1} \mathrm{P}$ from inorganic fertilizer.

Sympodial branches reflect the combined response of genetic makeup and environmental conditions. An increase in this attribute may result in more bolls per plant, which (a)

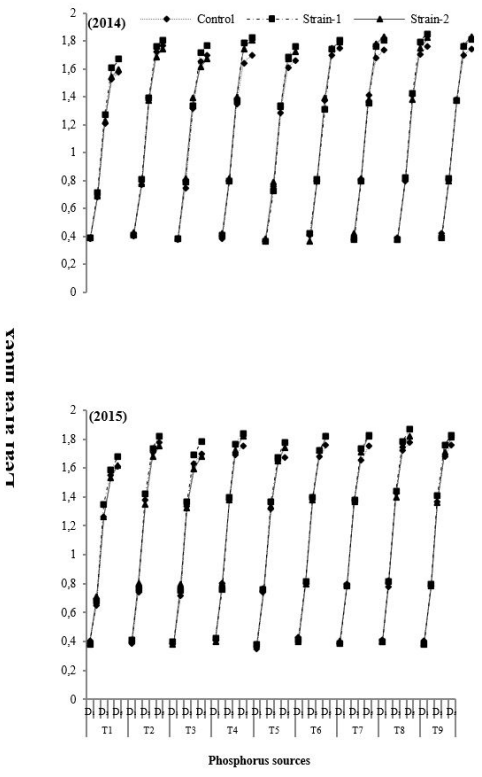

(b)

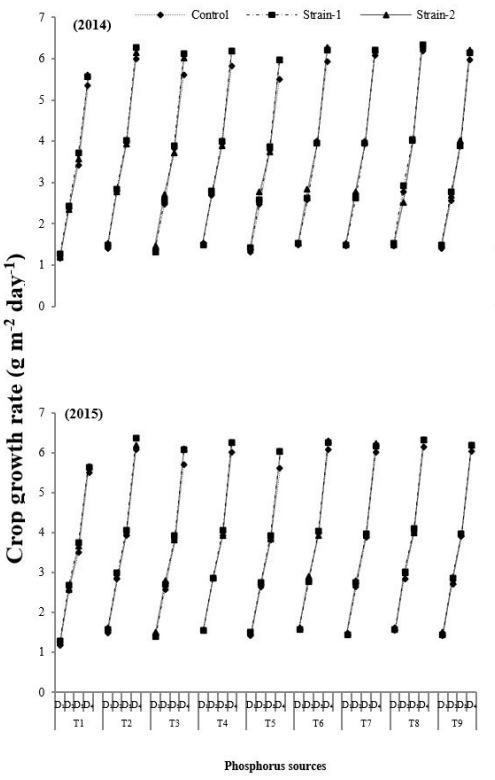

(c)

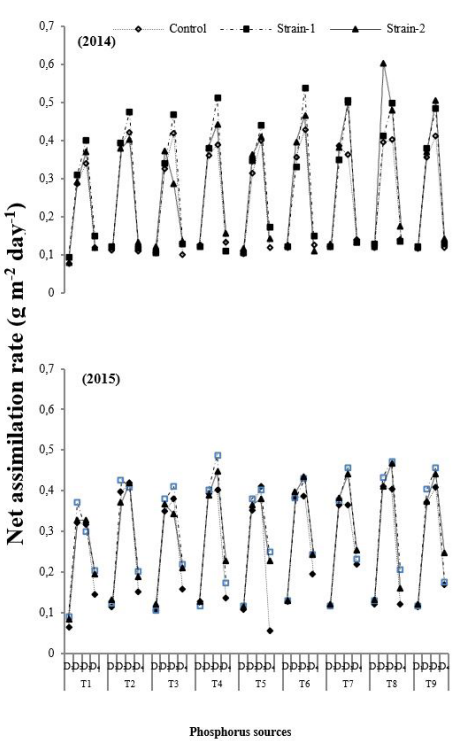

Figure 1. Influence of PSB strains and P sources on LAI (a) CGR (b) and NAR (c) of cotton. 
(a)

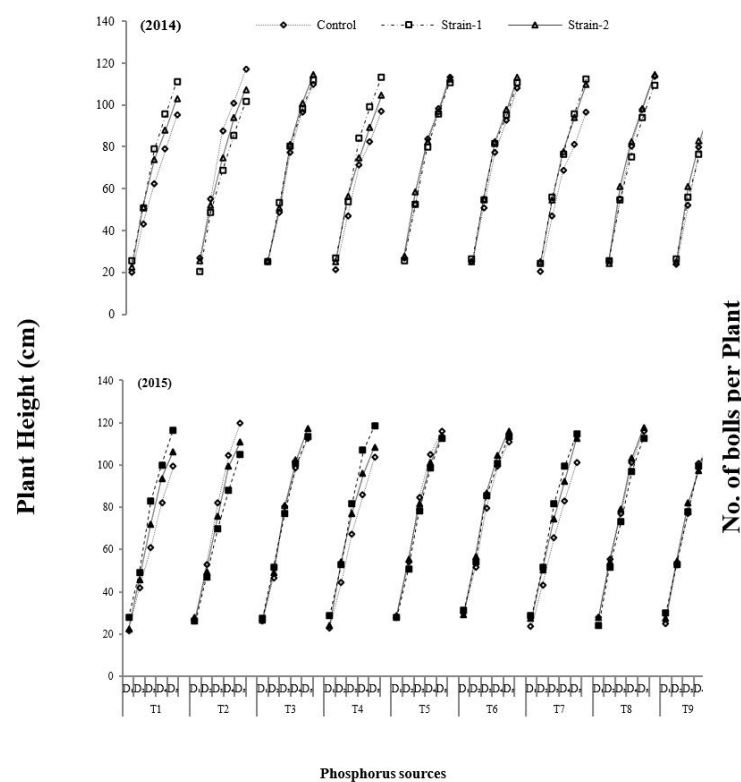

(b)

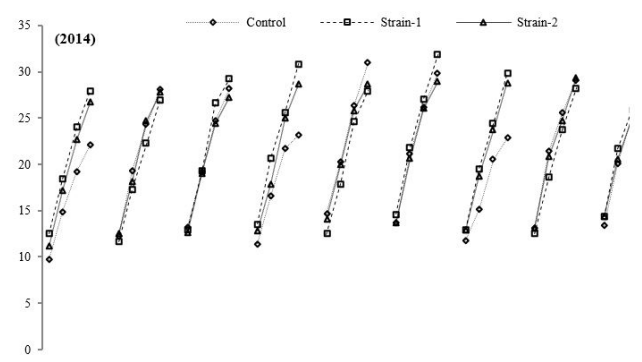

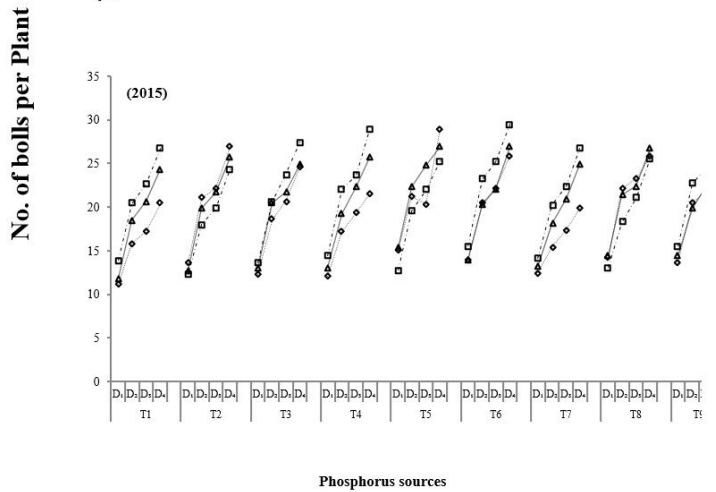

Figure 2. Influence of PSB strains and P sources plant height (a) number of bolls per plant (b) of cotton.

eventually enhance the productivity. The data concerning the number of sympodial branches denoted significant interactive effects between strains of PSB and various organic and inorganic sources of P during both years (Table 1). Superior sympodial branches were noted with the integrated use of $80 \mathrm{~kg} \mathrm{ha}^{-1} \mathrm{P}$ from $\mathrm{PM}+40 \mathrm{~kg} \mathrm{ha}^{-1} \mathrm{P}$ from inorganic source and where seed inoculation with strain-1 of PSB was done during first growing season. While minimum sympodial branches were verified in control treatment. Whereas, higher number of sympodial branches was observed where $40 \mathrm{~kg} \mathrm{ha}^{-1} \mathrm{P}$ from $\mathrm{PM}+40 \mathrm{~kg} \mathrm{ha}^{-1} \mathrm{P}$ from inorganic source was followed in cotton field inoculated with strain-1 of PSB in 2015. Significantly lower sympodial branches were noted from control plots .

Number of bolls per plant was significantly influenced at various growth periods by PSB strains and distinctive sources of P during both years (Figure $2 b$ ). Integrated use of $80 \mathrm{~kg} \mathrm{ha}^{-1} \mathrm{P}$ from $\mathrm{PM}+40 \mathrm{~kg} \mathrm{P} \mathrm{ha}{ }^{-1}$ from inorganic source in cotton field inoculated with strain-1 of PSB produced superior number of bolls at distinctive phases of plant sampling as compared to other treatments.

The data analysis showed significant effects of distinctive sources of P, PSB strains and their interaction on mean boll weight of cotton (Table 1). Integrated use of $80 \mathrm{~kg} \mathrm{ha}^{-1} \mathrm{P}$ from $\mathrm{PM}+40 \mathrm{~kg} \mathrm{ha}^{-1} \mathrm{P}$ from inorganic source in cotton field inoculated with strain-1 produced highest boll weight against the lowest boll weight noted in control treatment during Kharif 2014. While, collective use of $80 \mathrm{~kg} \mathrm{ha}^{-1}$ from P FYM $+40 \mathrm{~kg} \mathrm{ha}^{-1} \mathrm{P}$ from inorganic source along with similar bacterial strain produced maximum boll weight compared with minimum boll weight in control treatment in 2015.
Seed cotton yield data exhibited significant effects of distinctive organic and inorganic phosphorus sources, PSB strains and their interaction (Table 1). Cotton seeds inoculated with strain-1 produced maximum seed cotton yield with combined use of $80 \mathrm{~kg} \mathrm{ha}^{-1} \mathrm{P}$ from $\mathrm{PM}+40 \mathrm{~kg} \mathrm{ha}^{-1} \mathrm{P}$ from inorganic source. Lowest seed cotton yield was documented from control plots.

Data exposed significant influence of PSB strains, sources of applied P and their interaction on cotton lint yield (Table 2). Cotton seed inoculated with strain-1 and supplied $80 \mathrm{~kg} \mathrm{ha}^{-1} \mathrm{P}$ from $\mathrm{PM}+40 \mathrm{~kg} \mathrm{ha}^{-1} \mathrm{P}$ from inorganic source produced maximum lint yield against the minimum lint yield recorded in control treated plots during both years.

Data indicated that among distinctive sources of $\mathrm{P}$, maximum fiber fineness was recorded with the use of $80 \mathrm{~kg} \mathrm{ha}^{-1} \mathrm{P}$ from inorganic source and collective use of $80 \mathrm{~kg} \mathrm{ha}^{-1} \mathrm{P}$ from $\mathrm{PM}+40 \mathrm{~kg} \mathrm{ha}^{-1} \mathrm{P}$ from inorganic source against the minimum fiber fineness was documented in control plots during 2014 (Table 2). However, non-significant differences were observed for different applied P sources strains of PSB as well as their interaction regarding this attribute during 2015.

Data revealed that use of $80 \mathrm{~kg} \mathrm{Pha}^{-1}$ from PM $+40 \mathrm{~kg} \mathrm{ha}^{-1} \mathrm{P}$ from inorganic source along with inoculation strain-1 produced maximum fiber uniformity in 2014 and 2015 (Table 2). While minimum fiber uniformity observed under control treatment.

Significantly higher fiber length was noted with the use of $80 \mathrm{~kg} \mathrm{ha}^{-1} \mathrm{P}$ from $\mathrm{PM}+40 \mathrm{~kg} \mathrm{P} \mathrm{ha}^{-1}$ from inorganic source during 2014. Seed cotton inoculated with strain-1 and supplied $80 \mathrm{~kg} \mathrm{P} \mathrm{ha}^{-1}$ from inorganic source produced 
Table 1. Influence of PSB strains and P sources yield and yield contributing attributes of Bt cotton.

\begin{tabular}{|c|c|c|c|c|c|c|}
\hline \multirow{2}{*}{ Treatments } & \multicolumn{2}{|c|}{ Sympodial branches } & \multicolumn{2}{|c|}{ Mean Boll weight (g) } & \multicolumn{2}{|c|}{ Seed cotton yield $\left(\mathrm{kg} \mathrm{ha}^{-1}\right)$} \\
\hline & 2014 & 2015 & 2014 & 2015 & 2014 & 2015 \\
\hline \multicolumn{7}{|c|}{ Different sources of phosphorus } \\
\hline $\mathrm{P}_{0}$ & $21.92 \mathrm{~d}$ & $22.36 b$ & $2.87 \mathrm{c}$ & $2.78 b$ & $2601.6 \mathrm{c}$ & $2286.1 \mathrm{~d}$ \\
\hline $\mathrm{P}_{1}$ & $26.26 \mathrm{ac}$ & $27.71 \mathrm{a}$ & $2.95 \mathrm{ac}$ & $2.91 \mathrm{ab}$ & $3487.8 \mathrm{ab}$ & $3208.9 \mathrm{ab}$ \\
\hline $\mathrm{P}_{2}$ & $24.68 \mathrm{~cd}$ & $25.23 \mathrm{ab}$ & $2.89 \mathrm{bc}$ & $2.83 \mathrm{ab}$ & $3252.7 b$ & $2828.8 \mathrm{c}$ \\
\hline $\mathrm{P}_{3}$ & $26.88 \mathrm{ac}$ & $27.32 \mathrm{a}$ & $2.97 \mathrm{ab}$ & $2.91 \mathrm{ab}$ & $3494.1 \mathrm{ab}$ & $3167.2 \mathrm{ab}$ \\
\hline $\mathrm{P}_{4}$ & $25.41 b c$ & $26.30 \mathrm{a}$ & $2.91 \mathrm{ac}$ & $2.87 \mathrm{ab}$ & $3225.2 b$ & $2883.9 \mathrm{bc}$ \\
\hline $\mathrm{P}_{5}$ & $26.61 \mathrm{ac}$ & $27.61 \mathrm{a}$ & $2.97 \mathrm{ab}$ & $2.94 \mathrm{a}$ & $3390.6 \mathrm{ab}$ & $3114.1 \mathrm{ac}$ \\
\hline $\mathrm{P}_{6}$ & $27.83 \mathrm{ab}$ & $28.06 \mathrm{a}$ & $2.98 \mathrm{ab}$ & $2.94 \mathrm{a}$ & $3526.1 \mathrm{ab}$ & $3039.2 b c$ \\
\hline $\mathrm{P}_{7}$ & $28.72 \mathrm{a}$ & $27.04 \mathrm{a}$ & $3.00 \mathrm{a}$ & $2.96 \mathrm{a}$ & $3695.6 \mathrm{a}$ & $3376.0 \mathrm{a}$ \\
\hline $\mathrm{P}_{8}$ & $26.97 \mathrm{ac}$ & $28.19 a$ & $2.96 \mathrm{ac}$ & $2.92 \mathrm{a}$ & $3404.7 \mathrm{ab}$ & $3062.7 \mathrm{ac}$ \\
\hline LSD & 2.8121 & 3.8839 & 0.0946 & 0.1390 & 357.48 & 329.67 \\
\hline \multicolumn{7}{|c|}{ Different strains of phosphate solubilizing bacteria } \\
\hline $\mathrm{S}_{0}$ & 25.69 & 26.24 & $2.91 \mathrm{~b}$ & $2.84 b$ & $3165.2 b$ & $2849.1 b$ \\
\hline $\mathrm{S}_{1}$ & 26.79 & 27.42 & $2.99 \mathrm{a}$ & $2.95 \mathrm{a}$ & $3475.2 \mathrm{a}$ & $3142.2 \mathrm{a}$ \\
\hline $\mathrm{S}_{2}$ & 25.95 & 26.58 & $2.93 b$ & $2.90 \mathrm{ab}$ & $3385.6 \mathrm{a}$ & $2997.7 \mathrm{ab}$ \\
\hline LSD & n.s & n.s & 0.0546 & 0.0802 & 206.39 & 190.34 \\
\hline \multicolumn{7}{|c|}{ Interaction } \\
\hline $\mathrm{P}_{0} \mathrm{~S}_{0}$ & $21.11 \mathrm{e}$ & $22.44 b c$ & $2.83 \mathrm{~d}$ & $2.70 \mathrm{c}$ & $2510.5 f$ & $2186.8 \mathrm{~h}$ \\
\hline $\mathrm{P}_{0} \mathrm{~S}_{1}$ & $22.53 \mathrm{ce}$ & $23.20 \mathrm{ac}$ & $2.90 \mathrm{bd}$ & $2.84 \mathrm{ac}$ & $2683.8 \mathrm{df}$ & $2438.1 \mathrm{fh}$ \\
\hline $\mathrm{P}_{0} \mathrm{~S}_{2}$ & $22.12 \mathrm{de}$ & $21.45 \mathrm{c}$ & $2.87 \mathrm{~cd}$ & $2.81 \mathrm{ac}$ & $2610.4 \mathrm{ef}$ & $2233.3 \mathrm{gh}$ \\
\hline $\mathrm{P}_{1} \mathrm{~S}_{0}$ & $25.60 \mathrm{ae}$ & $26.30 \mathrm{ac}$ & $2.91 \mathrm{bd}$ & $2.84 \mathrm{ac}$ & $3246.3 \mathrm{bd}$ & 3053.6ae \\
\hline $\mathrm{P}_{1} \mathrm{~S}_{1}$ & $26.89 a$ & $28.55 \mathrm{ab}$ & $2.99 \mathrm{ad}$ & $2.95 \mathrm{ab}$ & $3694.3 \mathrm{ac}$ & $3416.0 \mathrm{ac}$ \\
\hline $\mathrm{P}_{1} \mathrm{~S}_{2}$ & $26.31 \mathrm{ad}$ & $27.64 \mathrm{ac}$ & $2.96 \mathrm{ad}$ & $2.94 \mathrm{ab}$ & $3522.8 \mathrm{ac}$ & $3157.1 \mathrm{ae}$ \\
\hline $\mathrm{P}_{2} \mathrm{~S}_{0}$ & $23.64 \mathrm{be}$ & $24.31 \mathrm{ac}$ & $2.87 \mathrm{~cd}$ & $2.79 b c$ & $3077.7 \mathrm{cf}$ & $2722.6 \mathrm{eh}$ \\
\hline $\mathrm{P}_{2} \mathrm{~S}_{1}$ & $25.38 \mathrm{ae}$ & $25.71 \mathrm{ac}$ & $2.91 \mathrm{bd}$ & $2.84 \mathrm{ac}$ & $3343.0 \mathrm{ac}$ & $2910.9 b f$ \\
\hline $\mathrm{P}_{2} \mathrm{~S}_{2}$ & $25.01 \mathrm{ae}$ & $25.68 \mathrm{ac}$ & $2.90 \mathrm{bd}$ & $2.87 \mathrm{ac}$ & $3337.2 \mathrm{ac}$ & $2852.8 \mathrm{cf}$ \\
\hline $\mathrm{P}_{3} \mathrm{~S}_{0}$ & $26.74 \mathrm{ad}$ & $27.07 \mathrm{ac}$ & $2.94 \mathrm{ad}$ & $2.83 \mathrm{ac}$ & $3290.0 \mathrm{bd}$ & $3023.3 \mathrm{ae}$ \\
\hline $\mathrm{P}_{3} \mathrm{~S}_{1}$ & $27.88 \mathrm{ab}$ & $27.55 \mathrm{ac}$ & $3.02 \mathrm{ac}$ & $2.99 \mathrm{ab}$ & $3749.9 \mathrm{ab}$ & $3458.6 \mathrm{ab}$ \\
\hline $\mathrm{P}_{3} \mathrm{~S}_{2}$ & $26.02 \mathrm{ad}$ & $27.35 \mathrm{ac}$ & $2.95 \mathrm{ad}$ & $2.9 \mathrm{abc}$ & $3442.5 \mathrm{ac}$ & $3019.8 \mathrm{ae}$ \\
\hline $\mathrm{P}_{4} \mathrm{~S}_{0}$ & $24.79 \mathrm{ae}$ & $26.13 \mathrm{ac}$ & $2.88 \mathrm{~cd}$ & $2.83 \mathrm{ac}$ & $3097.7 \mathrm{cf}$ & $2760.6 \mathrm{eg}$ \\
\hline $\mathrm{P}_{4} \mathrm{~S}_{1}$ & $24.75 \mathrm{ae}$ & $27.37 \mathrm{ac}$ & $2.94 \mathrm{ad}$ & $2.90 \mathrm{ac}$ & $3273.2 \mathrm{bd}$ & 2938.6bf \\
\hline $\mathrm{P}_{4} \mathrm{~S}_{2}$ & $26.70 \mathrm{ad}$ & $25.41 \mathrm{ac}$ & $2.92 \mathrm{ad}$ & $2.89 \mathrm{ac}$ & $3304.6 b c$ & 2952.6bf \\
\hline $\mathrm{P}_{5}^{4} \mathrm{~S}_{0}^{2}$ & $25.60 \mathrm{ae}$ & $25.94 \mathrm{ac}$ & $2.94 \mathrm{ad}$ & $2.90 \mathrm{ac}$ & $3252.5 \mathrm{bd}$ & $2982.5 b f$ \\
\hline $\mathrm{P}_{5} \mathrm{~S}_{1}$ & $27.88 \mathrm{ab}$ & $29.21 \mathrm{a}$ & $3.00 \mathrm{ac}$ & $2.98 \mathrm{ab}$ & $3436.8 \mathrm{ac}$ & $3209.5 \mathrm{ae}$ \\
\hline $\mathrm{P}_{5} \mathrm{~S}_{2}$ & $26.35 \mathrm{ad}$ & $27.69 \mathrm{ac}$ & $2.96 \mathrm{ad}$ & $2.94 \mathrm{ac}$ & $3482.5 \mathrm{ac}$ & $3150.3 \mathrm{ae}$ \\
\hline $\mathrm{P}_{6} \mathrm{~S}_{0}$ & $27.55 \mathrm{ab}$ & $26.89 \mathrm{ac}$ & $2.94 \mathrm{ad}$ & $2.88 \mathrm{ac}$ & $3334.7 \mathrm{ac}$ & $2813.6 \mathrm{df}$ \\
\hline $\mathrm{P}_{6} \mathrm{~S}_{1}$ & $28.17 \mathrm{ab}$ & $28.84 \mathrm{ab}$ & $3.06 \mathrm{ab}$ & $3.03 \mathrm{a}$ & $3664.7 \mathrm{ac}$ & $3137.3 \mathrm{ae}$ \\
\hline $\mathrm{P}_{6} \mathrm{~S}_{2}$ & $27.77 \mathrm{ab}$ & $28.44 \mathrm{ab}$ & $2.93 \mathrm{ad}$ & $2.90 \mathrm{ac}$ & $3579.0 \mathrm{ac}$ & $3166.6 \mathrm{ae}$ \\
\hline $\mathrm{P}_{7} \mathrm{~S}_{0}$ & $28.89 a$ & $27.89 \mathrm{ac}$ & $2.97 \mathrm{ad}$ & $2.93 \mathrm{ac}$ & $3480.9 \mathrm{ac}$ & $3204.2 \mathrm{ae}$ \\
\hline $\mathrm{P}_{7} \mathrm{~S}_{1}$ & $29.10 \mathrm{a}$ & $28.44 \mathrm{ab}$ & $3.09 \mathrm{a}$ & $3.02 \mathrm{ab}$ & $3933.9 a$ & $3560.5 \mathrm{a}$ \\
\hline $\mathrm{P}_{7} \mathrm{~S}_{2}$ & $28.17 \mathrm{ab}$ & $27.50 \mathrm{ac}$ & $2.94 \mathrm{ad}$ & $2.92 \mathrm{ac}$ & $3672.0 \mathrm{ac}$ & $3363.2 \mathrm{ad}$ \\
\hline $\mathrm{P}_{8} \mathrm{~S}_{0}$ & $27.26 \mathrm{ac}$ & $28.60 \mathrm{ab}$ & $2.93 \mathrm{ad}$ & $2.90 \mathrm{ac}$ & 3197.0be & 2894.5bf \\
\hline $\mathrm{P}_{8} \mathrm{~S}_{1}$ & $26.62 \mathrm{ad}$ & $27.95 \mathrm{ac}$ & $3.02 \mathrm{ac}$ & $2.97 \mathrm{ab}$ & $3497.3 \mathrm{ac}$ & $3210.1 \mathrm{ae}$ \\
\hline $\mathrm{P}_{8} \mathrm{~S}_{2}$ & $27.03 \mathrm{ac}$ & $28.03 \mathrm{ac}$ & $2.93 \mathrm{ad}$ & $2.89 \mathrm{ac}$ & $3519.8 \mathrm{ac}$ & $3083.3 \mathrm{ae}$ \\
\hline LSD & 4.8707 & 6.7271 & 0.1639 & 0.2407 & 619.17 & 571.01 \\
\hline
\end{tabular}

Whereas $\mathrm{S}_{0}=$ control; $\mathrm{S}_{1}=$ strain- $1 ; \mathrm{S}_{2}=$ strain $-2 ; \mathrm{P}_{1}=80 \mathrm{~kg} \mathrm{ha}^{-1} \mathrm{P}$ from inorganic source $; \mathrm{P}_{2}=80 \mathrm{~kg} \mathrm{ha}^{-1} \mathrm{P}$ from FYM; $\mathrm{P}_{3}=80 \mathrm{~kg}$ ha ${ }^{-1}$ $\mathrm{P}$ from PM; $\mathrm{P}_{4}=40 \mathrm{~kg} \mathrm{ha}^{-1} \mathrm{P}$ from FYM $+40 \mathrm{~kg} \mathrm{ha}^{-1} \mathrm{P}$ from inorganic source; $\mathrm{P}_{5}=40 \mathrm{~kg} \mathrm{ha}^{-1} \mathrm{P}$ from PM $+40 \mathrm{~kg}^{-1} \mathrm{P}$ from inorganic source; $\mathrm{P}_{6}=80 \mathrm{~kg} \mathrm{ha}^{-1} \mathrm{P}$ from FYM $+40 \mathrm{~kg} \mathrm{ha}^{-1} \mathrm{P}$ from inorganic source; $\mathrm{P}_{7}=80 \mathrm{~kg} \mathrm{ha}^{-1} \mathrm{P}$ from PM $+40 \mathrm{~kg} \mathrm{ha}^{-1} \mathrm{P}$ from inorganic source; and $\mathrm{P}_{8}=40 \mathrm{~kg} \mathrm{ha}^{-1} \mathrm{P}$ from FYM $+40 \mathrm{~kg} \mathrm{ha}^{-1} \mathrm{P}$ from PM. LSD: Least Significant Difference; n.s: Non Significant. Means followed by same letters (s) are not significantly different at $\mathrm{P}<0.05$. 
Table 2. Influence of PSB strains and P sources fiber and fiber quality attributes of Bt cotton.

\begin{tabular}{|c|c|c|c|c|c|c|}
\hline \multirow{2}{*}{ Treatments } & \multicolumn{2}{|c|}{ Lint yield (kg ha $\left.{ }^{-1}\right)$} & \multicolumn{2}{|c|}{ fiber fineness $\left(\mu\right.$ inch $\left.^{-1}\right)$} & \multicolumn{2}{|c|}{ fiber uniformity } \\
\hline & 2014 & 2015 & 2014 & 2015 & 2014 & 2015 \\
\hline \multicolumn{7}{|c|}{ Different sources of phosphorus } \\
\hline $\mathrm{P}_{0}$ & $1015.3 \mathrm{~d}$ & $915.3 \mathrm{c}$ & $3.91 \mathrm{~b}$ & 3.99 & $82.35 b$ & $82.30 \mathrm{~b}$ \\
\hline $\mathrm{P}_{1}$ & $1388.4 \mathrm{ac}$ & $1288.4 \mathrm{ab}$ & $4.14 \mathrm{a}$ & 4.18 & $82.64 a$ & $82.67 \mathrm{a}$ \\
\hline $\mathrm{P}_{2}$ & $1294.9 \mathrm{c}$ & $1161.6 \mathrm{ab}$ & $4.05 \mathrm{ab}$ & 4.08 & $82.52 \mathrm{ab}$ & $82.54 \mathrm{a}$ \\
\hline $\mathrm{P}_{3}$ & $1403.7 \mathrm{ac}$ & $1281.5 \mathrm{ab}$ & $4.10 \mathrm{ab}$ & 4.16 & $82.62 \mathrm{a}$ & $82.63 a$ \\
\hline $\mathrm{P}_{4}$ & $1283.1 \mathrm{c}$ & $1172.0 \mathrm{~b}$ & $4.04 \mathrm{ab}$ & 4.07 & $82.52 \mathrm{ab}$ & $82.49 \mathrm{ab}$ \\
\hline $\mathrm{P}_{5}$ & $1358.0 \mathrm{bc}$ & $1235.8 b$ & $4.05 \mathrm{ab}$ & 4.10 & $82.59 \mathrm{a}$ & $82.64 a$ \\
\hline $\mathrm{P}_{6}$ & $1439.4 \mathrm{ab}$ & $1250.5 \mathrm{ab}$ & $4.05 \mathrm{ab}$ & 4.04 & $82.54 \mathrm{ab}$ & $82.59 \mathrm{a}$ \\
\hline $\mathrm{P}_{7}$ & $1506.5 \mathrm{a}$ & $1384.3 \mathrm{a}$ & $4.14 \mathrm{a}$ & 4.16 & $82.66 \mathrm{a}$ & $82.69 \mathrm{a}$ \\
\hline $\mathrm{P}_{8}$ & $1377.2 \mathrm{ac}$ & $1238.3 b$ & $4.09 \mathrm{ab}$ & 4.10 & $82.60 \mathrm{a}$ & $82.59 a$ \\
\hline LSD & 138.96 & 137.58 & 0.1863 & & 0.2129 & 0.2068 \\
\hline \multicolumn{7}{|c|}{ Different strains of phosphate solubilizing bacteria } \\
\hline $\mathrm{S}_{0}$ & $1256.5 b$ & $1152.1 \mathrm{~b}$ & 4.02 & 4.06 & $82.52 b$ & 82.52 \\
\hline $\mathrm{S}_{1}$ & $1391.5 \mathrm{a}$ & $1261.8 \mathrm{a}$ & 4.07 & 4.12 & $82.65 \mathrm{a}$ & 82.62 \\
\hline $\mathrm{S}_{2}$ & $1374.2 \mathrm{a}$ & $1228.6 \mathrm{ab}$ & 4.07 & 4.11 & $82.51 b$ & 82.57 \\
\hline LSD & 80.23 & 79.433 & n.s & n.s & 0.1229 & n.s \\
\hline \multicolumn{7}{|c|}{ Interaction } \\
\hline $\mathrm{P}_{0} \mathrm{~S}_{0}$ & $972.2 \mathrm{f}$ & $865.5 \mathrm{~g}$ & 3.90 & 3.98 & $82.30 \mathrm{~d}$ & $82.24 d$ \\
\hline $\mathrm{P}_{0} \mathrm{~S}_{1}$ & 1039.9ef & $973.3 \mathrm{eg}$ & 3.92 & 4.03 & $82.40 \mathrm{bd}$ & $82.35 b d$ \\
\hline $\mathrm{P}_{0} \mathrm{~S}_{2}$ & $1033.9 \mathrm{ef}$ & $907.2 \mathrm{fg}$ & 3.93 & 3.96 & $82.34 \mathrm{~cd}$ & $82.30 \mathrm{~cd}$ \\
\hline $\mathrm{P}_{1} \mathrm{~S}_{0}$ & $1249.9 \mathrm{ce}$ & $1216.6 \mathrm{ad}$ & 4.09 & 4.19 & $82.53 \mathrm{ad}$ & $82.58 \mathrm{ad}$ \\
\hline $\mathrm{P}_{1} \mathrm{~S}_{1}$ & $1479.9 \mathrm{ac}$ & $1379.9 \mathrm{ac}$ & 4.14 & 4.18 & $82.72 \mathrm{ab}$ & $82.70 \mathrm{ab}$ \\
\hline $\mathrm{P}_{1} \mathrm{~S}_{2}$ & $1435.3 \mathrm{ad}$ & $1268.6 \mathrm{ad}$ & 4.18 & 4.16 & $82.66 \mathrm{ad}$ & $82.72 \mathrm{a}$ \\
\hline $\mathrm{P}_{2} \mathrm{~S}_{0}$ & $1222.6 \mathrm{de}$ & $1122.6 \mathrm{df}$ & 3.99 & 4.04 & $82.45 \mathrm{ad}$ & $82.49 \mathrm{ad}$ \\
\hline $\mathrm{P}_{2} \mathrm{~S}_{1}$ & $1329.9 \mathrm{bd}$ & $1196.5 \mathrm{ae}$ & 4.06 & 4.11 & $82.63 \mathrm{ad}$ & $82.60 \mathrm{ac}$ \\
\hline $\mathrm{P}_{2} \mathrm{~S}_{2}$ & $1332.3 \mathrm{bd}$ & $1165.7 \mathrm{ce}$ & 4.11 & 4.10 & $82.47 \mathrm{ad}$ & $82.53 \mathrm{ad}$ \\
\hline $\mathrm{P}_{3} \mathrm{~S}_{0}$ & $1296.3 \mathrm{bd}$ & $1229.7 \mathrm{ad}$ & 4.14 & 4.17 & $82.64 \mathrm{ad}$ & $82.60 \mathrm{ac}$ \\
\hline $\mathrm{P}_{3} \mathrm{~S}_{1}$ & $1509.5 \mathrm{ab}$ & $1376.2 \mathrm{ac}$ & 4.07 & 4.19 & $82.67 \mathrm{ad}$ & $82.71 \mathrm{ab}$ \\
\hline $\mathrm{P}_{3} \mathrm{~S}_{2}$ & $1405.3 \mathrm{ad}$ & $1238.6 \mathrm{ad}$ & 4.10 & 4.13 & $82.55 \mathrm{ad}$ & $82.60 \mathrm{ac}$ \\
\hline $\mathrm{P}_{4} \mathrm{~S}_{0}$ & $1207.0 \mathrm{df}$ & $1107.0 \mathrm{df}$ & 3.94 & 3.99 & $82.39 \mathrm{bd}$ & $82.36 \mathrm{bd}$ \\
\hline $\mathrm{P}_{4} \mathrm{~S}_{1}$ & $1309.0 \mathrm{bd}$ & $1209.0 \mathrm{ae}$ & 4.07 & 4.10 & $82.67 \mathrm{ac}$ & $82.61 \mathrm{ac}$ \\
\hline $\mathrm{P}_{4} \mathrm{~S}_{2}$ & $1333.3 \mathrm{bd}$ & $1200.0 \mathrm{ae}$ & 4.10 & 4.13 & $82.48 \mathrm{ad}$ & $82.51 \mathrm{ad}$ \\
\hline $\mathrm{P}_{5} \mathrm{~S}_{0}$ & $1291.9 \mathrm{bd}$ & $1191.9 \mathrm{ae}$ & 3.98 & 4.01 & $82.57 \mathrm{ad}$ & $82.62 \mathrm{ac}$ \\
\hline $\mathrm{P}_{5} \mathrm{~S}_{1}$ & $1374.5 \mathrm{ad}$ & $1241.2 \mathrm{ad}$ & 4.05 & 4.08 & $82.69 \mathrm{ac}$ & $82.66 \mathrm{ab}$ \\
\hline $\mathrm{P}_{5} \mathrm{~S}_{2}$ & $1407.6 \mathrm{ad}$ & $1274.3 \mathrm{ad}$ & 4.13 & 4.19 & $82.52 \mathrm{ad}$ & $82.66 \mathrm{ab}$ \\
\hline $\mathrm{P}_{6} \mathrm{~S}_{0}$ & $1340.4 \mathrm{bd}$ & $1173.8 \mathrm{be}$ & 4.04 & 4.03 & $82.59 \mathrm{ad}$ & $82.63 \mathrm{ac}$ \\
\hline $\mathrm{P}_{6} \mathrm{~S}_{1}$ & $1487.2 \mathrm{ac}$ & $1253.9 \mathrm{ad}$ & 4.00 & 4.04 & $82.53 \mathrm{ad}$ & $82.58 \mathrm{ad}$ \\
\hline $\mathrm{P}_{6} \mathrm{~S}_{2}$ & $1490.6 \mathrm{ab}$ & $1324.0 \mathrm{ad}$ & 4.10 & 4.07 & $82.51 \mathrm{ad}$ & $82.55 \mathrm{ad}$ \\
\hline $\mathrm{P}_{7} \mathrm{~S}_{0}$ & $1412.9 \mathrm{ad}$ & $1312.9 \mathrm{ad}$ & 4.09 & 4.11 & $82.62 \mathrm{ad}$ & $82.66 \mathrm{ab}$ \\
\hline $\mathrm{P}_{7} \mathrm{~S}_{1}$ & $1594.9 \mathrm{a}$ & $1428.2 \mathrm{a}$ & 4.18 & 4.21 & $82.78 \mathrm{a}$ & $82.73 a$ \\
\hline $\mathrm{P}_{7} \mathrm{~S}_{2}$ & $1511.9 \mathrm{ab}$ & $1411.9 \mathrm{ab}$ & 4.16 & 4.14 & $82.59 \mathrm{ad}$ & $82.68 \mathrm{ab}$ \\
\hline $\mathrm{P}_{8} \mathrm{~S}_{0}^{2}$ & $1315.6 \mathrm{bd}$ & 1148.9 ce & 4.01 & 4.04 & $82.56 \mathrm{ad}$ & $82.53 \mathrm{ad}$ \\
\hline $\mathrm{P}_{8} \mathrm{~S}_{1}$ & $1398.3 \mathrm{ad}$ & $1298.3 \mathrm{ad}$ & 4.11 & 4.16 & $82.71 \mathrm{ab}$ & $82.65 \mathrm{ac}$ \\
\hline $\mathrm{P}_{8} \mathrm{~S}_{2}$ & $1417.6 \mathrm{ad}$ & $1267.6 \mathrm{ad}$ & 4.16 & 4.11 & $82.52 \mathrm{ad}$ & $82.58 \mathrm{ad}$ \\
\hline LSD & 240.68 & 238.30 & n.s & n.s & 0.3688 & 0.3581 \\
\hline
\end{tabular}

Whereas $\mathrm{S}_{0}=$ control; $\mathrm{S}_{1}=$ strain- $1 ; \mathrm{S}_{2}=$ strain- $2 ; \mathrm{P}_{1}=80 \mathrm{~kg} \mathrm{ha}^{-1} \mathrm{P}$ from inorganic source; $\mathrm{P}_{2}=80 \mathrm{~kg} \mathrm{ha}^{-1} \mathrm{P}$ from FYM; $\mathrm{P}_{3}=80 \mathrm{~kg}$ ha ${ }^{-1} \mathrm{P}$ from PM; $\mathrm{P}_{4}=40 \mathrm{~kg} \mathrm{ha}^{-1} \mathrm{P}$ from FYM $+40 \mathrm{~kg} \mathrm{ha}^{-1} \mathrm{P}$ from inorganic source; $\mathrm{P}_{5}=40 \mathrm{~kg} \mathrm{ha}^{-1} \mathrm{P}$ from $\mathrm{PM}+40 \mathrm{~kg}^{-1} \mathrm{P}$ from inorganic source; $\mathrm{P}_{6}=80 \mathrm{~kg} \mathrm{ha}^{-1} \mathrm{P}$ from FYM $+40 \mathrm{~kg} \mathrm{ha}^{-1} \mathrm{P}$ from inorganic source; $\mathrm{P}_{7}=80 \mathrm{~kg} \mathrm{ha}^{-1} \mathrm{P}$ from $\mathrm{PM}+40 \mathrm{~kg} \mathrm{ha}^{-1} \mathrm{P}$ from inorganic source; and $\mathrm{P}_{8}=40 \mathrm{~kg} \mathrm{ha}^{-1} \mathrm{P}$ from FYM $+40 \mathrm{~kg} \mathrm{ha}^{-1} \mathrm{P}$ from PM. LSD: Least Significant Difference; n.s: Non Significant. Means followed by same letters (s) are not significantly different at $\mathrm{P}<0.05$. 
highest fiber length during 2015 (Table 3). Lowest fiber length noted from control plots during both years.

Cotton seeds inoculated with strain- 2 and fertilized with $80 \mathrm{~kg} \mathrm{ha}^{-1} \mathrm{P}$ from PM produced highest fiber elongation during both growing seasons (Table 3). Lowest fiber elongation was documented in control plots.

Fiber strength determines the yarn spin ability, as weak fibers are hard to handle during manufacturing process (Saleem et al., 2010). Analysis of the data exhibited significant impact of P sources and interaction between PSB strains and distinctive sources of $\mathrm{P}$ on fiber strength of cotton during 2014 (Table 3). Use of $80 \mathrm{~kg} \mathrm{ha}^{-1} \mathrm{P}$ from inorganic source produced significantly higher fiber strength during 2014 while cotton seeds inoculated with PSB strain-1 and applied $80 \mathrm{~kg} \mathrm{ha}^{-1}$ from inorganic $\mathrm{P}$ source produced highest fiber strength during 2015. Lowest fiber strength documented in control plots during both years.

The realization of successful production techniques relies on two factors; first it should be easy to implement, second it should be inexpensive. The economics of the techniques is recorded on the basis of BCR that how much profit is accessible on the cost. Pursuing through the BCR considering treatments interaction, maximum BCR of 1.95 and 1.81 with net income of Rs. 1,43,560/and 1,16,503/- were received with the use of $80 \mathrm{~kg} \mathrm{ha}^{-1} \mathrm{P}$ from $\mathrm{PM}+40 \mathrm{~kg} \mathrm{P} \mathrm{ha}{ }^{-1}$ from inorganic source in cotton raised with inoculated seeds of strain-1 during 2014 and 2015, respectively (Table 4). While minimum BCR was noted from control plots.

Table 3. Influence of PSB strains and $\mathrm{P}$ sources fiber quality attributes of Bt cotton.

\begin{tabular}{|c|c|c|c|c|c|c|}
\hline \multirow{2}{*}{ Treatments } & \multicolumn{2}{|c|}{ Fiber length (mm) } & \multicolumn{2}{|c|}{ Fiber elongation (\%) } & \multicolumn{2}{|c|}{ Fiber strength $\left(\mathrm{g} \mathrm{tex}^{-1}\right)$} \\
\hline & 2014 & 2015 & 2014 & 2015 & 2014 & 2015 \\
\hline \multicolumn{7}{|c|}{ Different sources of phosphorus } \\
\hline $\mathrm{P}_{0}$ & $26.34 b$ & $26.36 b$ & $6.34 \mathrm{c}$ & $6.36 \mathrm{~b}$ & $30.42 b$ & $30.42 b$ \\
\hline $\mathrm{P}_{1}$ & $26.72 \mathrm{a}$ & $26.79 \mathrm{a}$ & $6.71 \mathrm{ab}$ & $6.71 \mathrm{a}$ & $30.86 a$ & $30.88 \mathrm{a}$ \\
\hline $\mathrm{P}_{2}$ & $26.77 \mathrm{a}$ & $26.74 \mathrm{a}$ & $6.63 \mathrm{ab}$ & $6.62 \mathrm{a}$ & $30.70 \mathrm{a}$ & $30.71 \mathrm{a}$ \\
\hline $\mathrm{P}_{3}$ & $26.74 \mathrm{a}$ & $26.77 \mathrm{a}$ & $6.82 \mathrm{a}$ & $6.75 \mathrm{a}$ & $30.78 \mathrm{a}$ & $30.78 \mathrm{a}$ \\
\hline $\mathrm{P}_{4}$ & $26.69 \mathrm{a}$ & $26.68 \mathrm{a}$ & $6.60 \mathrm{~b}$ & $6.63 \mathrm{a}$ & $30.69 \mathrm{a}$ & $30.73 a$ \\
\hline $\mathrm{P}_{5}$ & $26.74 \mathrm{a}$ & $26.79 \mathrm{a}$ & $6.73 \mathrm{ab}$ & $6.72 \mathrm{a}$ & $30.77 \mathrm{a}$ & $30.79 \mathrm{a}$ \\
\hline $\mathrm{P}_{6}$ & $26.63 a$ & $26.69 \mathrm{a}$ & $6.63 \mathrm{ab}$ & $6.63 \mathrm{a}$ & $30.70 \mathrm{a}$ & $30.71 \mathrm{a}$ \\
\hline $\mathrm{P}_{7}$ & $26.80 \mathrm{a}$ & $26.81 \mathrm{a}$ & $6.72 \mathrm{ab}$ & $6.73 \mathrm{a}$ & $30.84 \mathrm{a}$ & $30.82 \mathrm{a}$ \\
\hline $\mathrm{P}_{8}$ & $26.71 \mathrm{a}$ & $26.79 \mathrm{a}$ & $6.66 \mathrm{ab}$ & $6.68 \mathrm{a}$ & $30.74 \mathrm{a}$ & $30.77 \mathrm{a}$ \\
\hline LSD & 0.2187 & 0.2205 & 0.2092 & 0.1878 & 0.2113 & 0.2015 \\
\hline \multicolumn{7}{|c|}{ Different strains of phosphate solubilizing bacteria } \\
\hline $\mathrm{S}_{0}$ & 26.71 & 26.72 & $6.59 \mathrm{~b}$ & $6.60 \mathrm{~b}$ & 30.74 & 30.73 \\
\hline $\mathrm{S}_{1}$ & 26.63 & 26.73 & $6.60 \mathrm{~b}$ & $6.62 \mathrm{ab}$ & 30.71 & 30.75 \\
\hline $\mathrm{S}_{2}$ & 26.70 & 26.69 & $6.74 \mathrm{a}$ & $6.72 \mathrm{a}$ & 30.71 & 30.73 \\
\hline LSD & n.s & n.s & 0.1208 & 0.1084 & n.s & n.s \\
\hline \multicolumn{7}{|c|}{ Interaction } \\
\hline $\mathrm{P}_{0} \mathrm{~S}_{0}$ & $26.26 \mathrm{~d}$ & $26.33 d$ & $6.28 \mathrm{e}$ & $6.32 \mathrm{e}$ & $30.34 d$ & $30.38 \mathrm{~d}$ \\
\hline $\mathrm{P}_{0} \mathrm{~S}_{1}$ & $26.32 \mathrm{~cd}$ & $26.38 b d$ & $6.33 \mathrm{de}$ & $6.39 \mathrm{ce}$ & $30.43 \mathrm{~cd}$ & $30.49 \mathrm{bd}$ \\
\hline $\mathrm{P}_{0} \mathrm{~S}_{2}$ & $26.43 \mathrm{bd}$ & $26.37 \mathrm{~cd}$ & $6.41 \mathrm{ce}$ & $6.35 \mathrm{de}$ & $30.49 \mathrm{bd}$ & $30.39 \mathrm{~cd}$ \\
\hline $\mathrm{P}_{1} \mathrm{~S}_{0}$ & $26.74 a b$ & $26.80 \mathrm{a}$ & $6.70 \mathrm{bc}$ & $6.67 \mathrm{ac}$ & $30.92 \mathrm{a}$ & $30.85 a$ \\
\hline $\mathrm{P}_{1} \mathrm{~S}_{1}$ & $26.67 \mathrm{ac}$ & $26.84 a$ & $6.66 \mathrm{bd}$ & $6.71 \mathrm{ac}$ & $30.90 \mathrm{a}$ & $30.94 a$ \\
\hline $\mathrm{P}_{1} \mathrm{~S}_{2}$ & $26.75 \mathrm{ab}$ & $26.72 \mathrm{ac}$ & $6.77 \mathrm{ac}$ & $6.74 \mathrm{ab}$ & $30.78 \mathrm{ac}$ & $30.85 a$ \\
\hline $\mathrm{P}_{2} \mathrm{~S}_{0}$ & $26.82 \mathrm{a}$ & $26.75 \mathrm{ab}$ & $6.53 \mathrm{be}$ & $6.60 \mathrm{ae}$ & $30.67 \mathrm{ad}$ & $30.70 \mathrm{ad}$ \\
\hline $\mathrm{P}_{2} \mathrm{~S}_{1}$ & $26.73 \mathrm{ab}$ & $26.77 \mathrm{a}$ & $6.69 \mathrm{bd}$ & $6.62 \mathrm{ae}$ & $30.65 \mathrm{ad}$ & $30.69 \mathrm{ad}$ \\
\hline $\mathrm{P}_{2} \mathrm{~S}_{2}$ & $26.75 \mathrm{ab}$ & $26.69 \mathrm{ad}$ & $6.67 \mathrm{bd}$ & $6.64 \mathrm{ae}$ & $30.78 \mathrm{ac}$ & $30.74 \mathrm{ab}$ \\
\hline $\mathrm{P}_{3} \mathrm{~S}_{0}$ & $26.88 \mathrm{a}$ & $26.83 \mathrm{a}$ & $6.72 \mathrm{ac}$ & $6.67 \mathrm{ac}$ & $30.79 \mathrm{ac}$ & $30.76 \mathrm{ab}$ \\
\hline $\mathrm{P}_{3} \mathrm{~S}_{1}$ & $26.69 \mathrm{ac}$ & $26.79 \mathrm{a}$ & $6.67 \mathrm{bd}$ & $6.69 \mathrm{ac}$ & $30.78 \mathrm{ac}$ & $30.80 \mathrm{ab}$ \\
\hline $\mathrm{P}_{3} \mathrm{~S}_{2}$ & $26.66 \mathrm{ac}$ & $26.70 \mathrm{ad}$ & $7.07 \mathrm{a}$ & $6.89 \mathrm{a}$ & $30.76 \mathrm{ac}$ & $30.79 \mathrm{ab}$ \\
\hline $\mathrm{P}_{4} \mathrm{~S}_{0}$ & $26.57 \mathrm{ad}$ & $26.64 \mathrm{ad}$ & $6.57 \mathrm{be}$ & $6.60 \mathrm{ae}$ & $30.67 \mathrm{ad}$ & $30.72 \mathrm{ad}$ \\
\hline $\mathrm{P}_{4} \mathrm{~S}_{4}$ & $26.64 \mathrm{ac}$ & $26.71 \mathrm{ac}$ & $6.54 \mathrm{be}$ & $6.51 \mathrm{be}$ & $30.65 \mathrm{ad}$ & $30.70 \mathrm{ad}$ \\
\hline
\end{tabular}

Whereas $\mathrm{S}_{0}=$ control; $\mathrm{S}_{1}=$ strain- $; \mathrm{S}_{2}=$ strain-2; $\mathrm{P}_{1}=80 \mathrm{~kg} \mathrm{ha}^{-1} \mathrm{P}$ from inorganic source; $\mathrm{P}_{2}=80 \mathrm{~kg}$ ha ${ }^{-1} \mathrm{P}$ from FYM; $\mathrm{P}_{3}=80 \mathrm{~kg}$ ha ${ }^{-1} \mathrm{P}$ from $\mathrm{PM} ; \mathrm{P}_{4}=40 \mathrm{~kg} \mathrm{ha}^{-1} \mathrm{P}$ from FYM $+40 \mathrm{~kg} \mathrm{ha}^{-1} \mathrm{P}$ from inorganic source; $\mathrm{P}_{5}=40 \mathrm{~kg} \mathrm{ha}^{-1} \mathrm{P}$ from $\mathrm{PM}+40 \mathrm{~kg} \mathrm{ha}^{-1} \mathrm{P}$ from inorganic source; $\mathrm{P}_{6}=80 \mathrm{~kg} \mathrm{ha}^{-1} \mathrm{P}$ from FYM $+40 \mathrm{~kg} \mathrm{ha}^{-1} \mathrm{P}$ from inorganic source; $\mathrm{P}_{7}=80 \mathrm{~kg} \mathrm{ha}^{-1} \mathrm{P}$ from $\mathrm{PM}+40 \mathrm{~kg} \mathrm{ha}^{-1} \mathrm{P}$ from inorganic source; and $\mathrm{P}_{8}=40 \mathrm{~kg} \mathrm{ha}^{-1} \mathrm{P}$ from FYM $+40 \mathrm{~kg} \mathrm{ha}^{-1} \mathrm{P}$ from PM. LSD: Least Significant Difference; n.s: Non Significant. Means followed by same letters (s) are not significantly different at $\mathrm{P}<0.05$. 
Table 3. Continued...

\begin{tabular}{|c|c|c|c|c|c|c|}
\hline \multirow{2}{*}{ Treatments } & \multicolumn{2}{|c|}{ Fiber length (mm) } & \multicolumn{2}{|c|}{ Fiber elongation (\%) } & \multicolumn{2}{|c|}{ Fiber strength $\left(\mathrm{g} \mathrm{tex}^{-1}\right)$} \\
\hline & 2014 & 2015 & 2014 & 2015 & 2014 & 2015 \\
\hline $\mathrm{P}_{4} \mathrm{~S}_{2}$ & $26.85 a$ & $26.68 \mathrm{ad}$ & $6.69 \mathrm{bd}$ & $6.79 \mathrm{ab}$ & $30.75 \mathrm{ac}$ & $30.78 \mathrm{ab}$ \\
\hline $\mathrm{P}_{5} \mathrm{~S}_{0}$ & $26.73 \mathrm{ab}$ & $26.78 \mathrm{a}$ & $6.70 b c$ & $6.67 \mathrm{ac}$ & $30.86 a b$ & $30.83 \mathrm{ab}$ \\
\hline $\mathrm{P}_{5} \mathrm{~S}_{1}$ & $26.72 \mathrm{ab}$ & $26.78 \mathrm{a}$ & $6.66 \mathrm{bd}$ & $6.70 \mathrm{ac}$ & $30.73 \mathrm{ac}$ & $30.79 \mathrm{ab}$ \\
\hline $\mathrm{P}_{5} \mathrm{~S}_{2}$ & $26.77 \mathrm{ab}$ & $26.80 \mathrm{a}$ & $6.82 \mathrm{ab}$ & $6.78 \mathrm{ab}$ & $30.72 \mathrm{ac}$ & $30.76 \mathrm{ab}$ \\
\hline $\mathrm{P}_{6} \mathrm{~S}_{0}$ & $26.64 \mathrm{ad}$ & 26.67ad & $6.59 \mathrm{be}$ & $6.62 \mathrm{ae}$ & $30.65 \mathrm{ad}$ & $30.68 \mathrm{ad}$ \\
\hline $\mathrm{P}_{6} \mathrm{~S}_{1}$ & $26.60 \mathrm{ad}$ & $26.70 \mathrm{ad}$ & $6.54 \mathrm{be}$ & $6.58 \mathrm{ae}$ & $30.77 \mathrm{ac}$ & $30.74 \mathrm{ab}$ \\
\hline $\mathrm{P}_{6} \mathrm{~S}_{2}$ & $26.65 \mathrm{ac}$ & $26.71 \mathrm{ac}$ & $6.75 \mathrm{ac}$ & $6.69 \mathrm{ac}$ & $30.69 \mathrm{ad}$ & $30.71 \mathrm{ad}$ \\
\hline $\mathrm{P}_{7} \mathrm{~S}_{0}$ & $26.90 \mathrm{a}$ & $26.84 a$ & $6.67 \mathrm{bd}$ & $6.65 \mathrm{ad}$ & $30.92 \mathrm{a}$ & $30.86 a$ \\
\hline $\mathrm{P}_{7} \mathrm{~S}_{1}$ & $26.70 \mathrm{ab}$ & $26.77 \mathrm{a}$ & $6.69 b c$ & $6.74 \mathrm{ab}$ & $30.84 a b$ & $30.81 \mathrm{ab}$ \\
\hline $\mathrm{P}_{7} \mathrm{~S}_{2}$ & $26.78 \mathrm{ab}$ & $26.82 \mathrm{a}$ & $6.79 \mathrm{ab}$ & $6.81 \mathrm{ab}$ & $30.78 \mathrm{ac}$ & $30.80 \mathrm{ab}$ \\
\hline $\mathrm{P}_{8} \mathrm{~S}_{0}$ & $26.86 \mathrm{a}$ & $26.85 \mathrm{a}$ & $6.58 \mathrm{be}$ & $6.61 \mathrm{ae}$ & $30.88 \mathrm{a}$ & $30.81 \mathrm{ab}$ \\
\hline $\mathrm{P}_{8} \mathrm{~S}_{1}$ & $26.62 \mathrm{ad}$ & $26.80 \mathrm{a}$ & $6.63 \mathrm{be}$ & $6.67 \mathrm{ad}$ & $30.69 \mathrm{ad}$ & $30.77 \mathrm{ab}$ \\
\hline $\mathrm{P}_{8} \mathrm{~S}_{2}$ & $26.66 \mathrm{ac}$ & $26.72 \mathrm{ac}$ & $6.77 \mathrm{ab}$ & $6.76 \mathrm{ab}$ & $30.66 \mathrm{ad}$ & $30.73 \mathrm{ac}$ \\
\hline LSD & 0.3789 & 0.3819 & 0.3624 & 0.3253 & 0.3659 & 0.3489 \\
\hline
\end{tabular}

Whereas $\mathrm{S}_{0}=$ control; $\mathrm{S}_{1}=$ strain-1; $\mathrm{S}_{2}=$ strain-2; $\mathrm{P}_{1}=80 \mathrm{~kg} \mathrm{ha}^{-1} \mathrm{P}$ from inorganic source; $\mathrm{P}_{2}=80 \mathrm{~kg} \mathrm{ha}^{-1} \mathrm{P}$ from FYM; $\mathrm{P}_{3}=80 \mathrm{~kg} \mathrm{ha}^{-1} \mathrm{P}$ from PM; $\mathrm{P}_{4}=40 \mathrm{~kg} \mathrm{ha}^{-1} \mathrm{P}$ from FYM $+40 \mathrm{~kg} \mathrm{ha}^{-1} \mathrm{P}$ from inorganic source; $\mathrm{P}_{5}=40 \mathrm{~kg} \mathrm{ha}^{-1} \mathrm{P}$ from $\mathrm{PM}+40 \mathrm{~kg}^{-1} \mathrm{P}^{3}$ from inorganic source; $\mathrm{P}_{6}=80 \mathrm{~kg} \mathrm{ha}^{-1} \mathrm{P}$ from FYM $+40 \mathrm{~kg} \mathrm{ha}^{-1} \mathrm{P}$ from inorganic source; $\mathrm{P}_{7}=80 \mathrm{~kg} \mathrm{ha}^{-1} \mathrm{P}$ from $\mathrm{PM}+40 \mathrm{~kg} \mathrm{ha}^{-1} \mathrm{P}$ from inorganic source; and $\mathrm{P}_{8}=40 \mathrm{~kg} \mathrm{ha}^{-1} \mathrm{P}$ from FYM $+40 \mathrm{~kg} \mathrm{ha}^{-1} \mathrm{P}$ from PM. LSD: Least Significant Difference; n.s: Non Significant. Means followed by same letters (s) are not significantly different at $\mathrm{P}<0.05$.

Table 4. Economic analysis of cotton as affected by PSB strains and phosphorus sources during the year 2014 and 2015.

\begin{tabular}{|c|c|c|c|c|c|c|c|c|c|c|}
\hline & \multicolumn{5}{|c|}{2014} & \multicolumn{5}{|c|}{2015} \\
\hline & $\begin{array}{l}\text { Cost } \\
\text { that } \\
\text { vary }\end{array}$ & $\begin{array}{l}\text { Total } \\
\text { cost }\end{array}$ & $\begin{array}{c}\text { Gross } \\
\text { income }\end{array}$ & $\begin{array}{c}\text { Net } \\
\text { income }\end{array}$ & BCR & $\begin{array}{l}\text { Cost } \\
\text { that } \\
\text { vary }\end{array}$ & $\begin{array}{l}\text { Total } \\
\text { cost }\end{array}$ & $\begin{array}{l}\text { Gross } \\
\text { income }\end{array}$ & $\begin{array}{c}\text { Net } \\
\text { income }\end{array}$ & BCR \\
\hline \multicolumn{11}{|c|}{ Different sources of phosphorus } \\
\hline $\mathrm{P}_{0}$ & 15610 & 124250 & 195120 & 70870 & 1.57 & 13717 & 122357 & 171457 & 49101 & 1.40 \\
\hline $\mathrm{P}_{1}$ & 32405 & 141045 & 261585 & 120540 & 1.85 & 30731 & 139371 & 240667 & 101296 & 1.73 \\
\hline $\mathrm{P}_{2}$ & 27116 & 135756 & 243953 & 108196 & 1.80 & 24573 & 133213 & 212160 & 78947 & 1.59 \\
\hline $\mathrm{P}_{3}$ & 29465 & 138105 & 262057 & 123953 & 1.90 & 27503 & 136143 & 237540 & 101397 & 1.74 \\
\hline $\mathrm{P}_{4}$ & 28890 & 137530 & 241890 & 104360 & 1.76 & 26842 & 135482 & 216293 & 80810 & 1.60 \\
\hline $\mathrm{P}_{5}$ & 30333 & 138973 & 254295 & 115322 & 1.83 & 28674 & 137314 & 233557 & 96244 & 1.70 \\
\hline $\mathrm{P}_{6}$ & 34496 & 143136 & 264458 & 121322 & 1.85 & 31574 & 140214 & 227940 & 87726 & 1.63 \\
\hline $\mathrm{P}_{7}$ & 36413 & 145053 & 277170 & 132117 & 1.91 & 34495 & 143135 & 253200 & 110065 & 1.77 \\
\hline $\mathrm{P}_{8}$ & 28478 & 137118 & 255353 & 118234 & 1.86 & 26426 & 135066 & 229702 & 94636 & 1.70 \\
\hline \multicolumn{11}{|c|}{ Different strains of phosphate solubilizing bacteria } \\
\hline $\mathrm{S}_{0}$ & 18991 & 127631 & 237390 & 109759 & 1.86 & 17095 & 125734.6 & 213683 & 87948 & 1.70 \\
\hline $\mathrm{S}_{1}$ & 25851 & 134491 & 260640 & 126149 & 1.94 & 23853 & 132493 & 235665 & 103172 & 1.78 \\
\hline $\mathrm{S}_{2}$ & 25314 & 133954 & 253920 & 119966 & 1.90 & 22986 & 131626 & 224827 & 93201 & 1.71 \\
\hline \multicolumn{11}{|c|}{ Interaction } \\
\hline $\mathrm{P}_{0} \mathrm{~S}_{0}$ & 15063 & 123703 & 188287 & 64585 & 1.52 & 13121 & 121761 & 164010 & 42249 & 1.35 \\
\hline $\mathrm{P}_{0} \mathrm{~S}_{1}$ & 21103 & 129743 & 201285 & 71542 & 1.55 & 19629 & 128269 & 182857 & 54589 & 1.43 \\
\hline $\mathrm{P}_{0} \mathrm{~S}_{2}$ & 20662 & 129302 & 195780 & 66478 & 1.51 & 18400 & 127040 & 167497 & 40458 & 1.32 \\
\hline $\mathrm{P}_{1} \mathrm{~S}_{0}$ & 30956 & 139596 & 243473 & 103877 & 1.74 & 29800 & 138440 & 229020 & 90580 & 1.65 \\
\hline $\mathrm{P}_{1} \mathrm{~S}_{1}$ & 38644 & 147284 & 277073 & 129789 & 1.88 & 36974 & 145614 & 256200 & 110586 & 1.76 \\
\hline $\mathrm{P}_{1} \mathrm{~S}_{2}$ & 37615 & 146255 & 264210 & 117955 & 1.81 & 35421 & 144061 & 236783 & 92722 & 1.64 \\
\hline $\mathrm{P}_{2} \mathrm{~S}_{0}$ & 26066 & 134706 & 230827 & 96121 & 1.71 & 23936 & 132576 & 204195 & 71619 & 1.54 \\
\hline $\mathrm{P}_{2} \mathrm{~S}_{1}$ & 32658 & 141298 & 250725 & 109427 & 1.77 & 30065 & 138705 & 218317 & 79612 & 1.57 \\
\hline
\end{tabular}

Whereas $\mathrm{S}_{0}=$ control; $\mathrm{S}_{1}=$ strain- $1 ; \mathrm{S}_{2}=$ strain- $2 ; \mathrm{P}_{1}=80 \mathrm{~kg} \mathrm{ha}^{-1} \mathrm{P}$ from inorganic source; $\mathrm{P}_{2}=80 \mathrm{~kg}^{-1} \mathrm{P}$ from FYM$; \mathrm{P}_{3}=80 \mathrm{~kg} \mathrm{ha} \mathrm{k}^{-1} \mathrm{P}$ from PM; $\mathrm{P}_{4}=40 \mathrm{~kg} \mathrm{ha}^{-1} \mathrm{P}$ from FYM $+40 \mathrm{~kg} \mathrm{ha}^{-1} \mathrm{P}$ from inorganic source; $\mathrm{P}_{5}=40 \mathrm{~kg} \mathrm{ha}^{-1} \mathrm{P}$ from PM $+40 \mathrm{~kg} \mathrm{ha}^{-1} \mathrm{P}$ from inorganic source; $\mathrm{P}_{6}=80 \mathrm{~kg} \mathrm{ha}^{-1} \mathrm{P}$ from FYM $+40 \mathrm{~kg} \mathrm{ha}^{-1} \mathrm{P}$ from inorganic source; $\mathrm{P}_{7}=80 \mathrm{~kg} \mathrm{ha}^{-1} \mathrm{P}$ from $\mathrm{PM}+40 \mathrm{~kg} \mathrm{ha}^{-1} \mathrm{P}$ from inorganic source; and $\mathrm{P}_{8}=40 \mathrm{~kg} \mathrm{ha}^{-1} \mathrm{P}$ from FYM $+40 \mathrm{~kg} \mathrm{ha}^{-1} \mathrm{P}$ from PM. BCR: Benefit Cost Ratio; LSD: Least Significant Difference. Means followed by same letters (s) are not significantly different at $\mathrm{P}<0.05$. 
Table 4. Continued...

\begin{tabular}{|c|c|c|c|c|c|c|c|c|c|c|}
\hline & \multicolumn{5}{|c|}{2014} & \multicolumn{5}{|c|}{2015} \\
\hline & $\begin{array}{l}\text { Cost } \\
\text { that } \\
\text { vary }\end{array}$ & $\begin{array}{l}\text { Total } \\
\text { cost }\end{array}$ & $\begin{array}{c}\text { Gross } \\
\text { income }\end{array}$ & $\begin{array}{c}\text { Net } \\
\text { income }\end{array}$ & BCR & $\begin{array}{l}\text { Cost } \\
\text { that } \\
\text { vary }\end{array}$ & $\begin{array}{l}\text { Total } \\
\text { cost }\end{array}$ & $\begin{array}{c}\text { Gross } \\
\text { income }\end{array}$ & $\begin{array}{c}\text { Net } \\
\text { income }\end{array}$ & BCR \\
\hline $\mathrm{P}_{2} \mathrm{~S}_{2}$ & 32623 & 141263 & 250290 & 109027 & 1.77 & 29717 & 138357 & 213960 & 75603 & 1.55 \\
\hline $\mathrm{P}_{3} \mathrm{~S}_{0}$ & 28240 & 136880 & 246750 & 109870 & 1.80 & 26640 & 135280 & 226747 & 91468 & 1.68 \\
\hline $\mathrm{P}_{3} \mathrm{~S}_{1}$ & 35999 & 144639 & 281242 & 136603 & 1.94 & 34252 & 142892 & 259395 & 116503 & 1.81 \\
\hline $\mathrm{P}_{3} \mathrm{~S}_{2}$ & 34155 & 142795 & 258187 & 115392 & 1.81 & 31619 & 140259 & 226485 & 86226 & 1.61 \\
\hline $\mathrm{P}_{4} \mathrm{~S}_{0}$ & 28125 & 136765 & 232327 & 95562 & 1.70 & 26103 & 134743 & 207045 & 72302 & 1.54 \\
\hline $\mathrm{P}_{4} \mathrm{~S}_{1}$ & 34178 & 142818 & 245490 & 102672 & 1.72 & 32171 & 140811 & 220395 & 79584 & 1.57 \\
\hline $\mathrm{P}_{4} \mathrm{~S}_{2}$ & 34367 & 143007 & 247845 & 104838 & 1.73 & 32255 & 140895 & 221445 & 80550 & 1.57 \\
\hline $\mathrm{P}_{5} \mathrm{~S}_{0}$ & 29504 & 138144 & 243937 & 105793 & 1.77 & 27884 & 136524 & 223687 & 87163 & 1.64 \\
\hline $\mathrm{P}_{5} \mathrm{~S}_{1}$ & 35610 & 144250 & 257760 & 113510 & 1.79 & 34246 & 142886 & 240713 & 97827 & 1.69 \\
\hline $\mathrm{P}_{5} \mathrm{~S}_{2}$ & 35884 & 144524 & 261187 & 116663 & 1.81 & 33891 & 142531 & 236273 & 93742 & 1.66 \\
\hline $\mathrm{P}_{6} \mathrm{~S}_{0}$ & 33347 & 141987 & 250103 & 108115 & 1.76 & 30221 & 138861 & 211020 & 72159 & 1.52 \\
\hline $\mathrm{P}_{6} \mathrm{~S}_{1}$ & 40327 & 148967 & 274853 & 125885 & 1.85 & 37163 & 145803 & 235298 & 89495 & 1.61 \\
\hline $\mathrm{P}_{6} \mathrm{~S}_{2}$ & 39813 & 148453 & 268425 & 119972 & 1.81 & 37339 & 145979 & 237495 & 91516 & 1.63 \\
\hline $\mathrm{P}_{7} \mathrm{~S}_{0}$ & 35124 & 143764 & 261067 & 117303 & 1.81 & 33464 & 142104 & 240315 & 98211 & 1.69 \\
\hline $\mathrm{P}_{7} \mathrm{~S}_{1}$ & 42842 & 151482 & 295043 & 143560 & 1.95 & 40602 & 149242 & 267037.5 & 117795 & 1.79 \\
\hline $\mathrm{P}_{7} \mathrm{~S}_{2}$ & 41271 & 149911 & 275400 & 125489 & 1.84 & 39418 & 148058 & 252240 & 104182 & 1.70 \\
\hline $\mathrm{P}_{8} \mathrm{~S}_{0}$ & 27232 & 135872 & 239775 & 103903 & 1.76 & 25417 & 134057 & 217087 & 83030 & 1.62 \\
\hline $\mathrm{P}_{8} \mathrm{~S}_{1}$ & 34034 & 142674 & 262297 & 119624 & 1.84 & 32311 & 140951 & 240757 & 99807 & 1.71 \\
\hline $\mathrm{P}_{8} \mathrm{~S}_{2}$ & 34169 & 142809 & 263985 & 121176 & 1.85 & 31550 & 140190 & 231247 & 91058 & 1.65 \\
\hline
\end{tabular}

Whereas $\mathrm{S}_{0}=$ control; $\mathrm{S}_{1}=$ strain- $1 ; \mathrm{S}_{2}=$ strain- $2 ; \mathrm{P}_{1}=80 \mathrm{~kg} \mathrm{ha}^{-1} \mathrm{P}$ from inorganic source; $\mathrm{P}_{2}=80 \mathrm{~kg} \mathrm{ha}^{-1} \mathrm{P}$ from FYM; $\mathrm{P}_{3}=80 \mathrm{~kg} \mathrm{ha}^{-1} \mathrm{P}$ from PM; $\mathrm{P}_{4}=40 \mathrm{~kg} \mathrm{ha}^{-1} \mathrm{P}$ from FYM $+40 \mathrm{~kg} \mathrm{ha}^{-1} \mathrm{P}$ from inorganic source; $\mathrm{P}_{5}=40 \mathrm{~kg} \mathrm{ha}^{-1} \mathrm{P}$ from $\mathrm{PM}+40 \mathrm{~kg}^{-1} \mathrm{P}$ from inorganic source; $\mathrm{P}_{6}=80 \mathrm{~kg} \mathrm{ha}^{-1} \mathrm{P}$ from FYM $+40 \mathrm{~kg} \mathrm{ha}^{-1} \mathrm{P}$ from inorganic source; $\mathrm{P}_{7}=80 \mathrm{~kg} \mathrm{ha}^{-1} \mathrm{P}$ from PM $+40 \mathrm{~kg} \mathrm{ha}^{-1} \mathrm{P}$ from inorganic source; and $\mathrm{P}_{8}=40 \mathrm{~kg} \mathrm{ha}^{-1} \mathrm{P}$ from FYM $+40 \mathrm{~kg} \mathrm{ha}^{-1} \mathrm{P}$ from PM. BCR: Benefit Cost Ratio; LSD: Least Significant Difference. Means followed by same letters (s) are not significantly different at $\mathrm{P}<0.05$.

\section{Discussion}

Cotton plants demand optimum quantity of phosphorus from germination to maturity as it develops numerous mechanism of plant that encourages the root growth, strengthens the stem, improves the flower and boll development (Saleem et al., 2010). Therefore, multiple approaches were adopted to increase phosphorus availability in present study. Cotton seeds inoculated with strain-1 of PSB produced significantly higher growth attributes with the use of $80 \mathrm{~kg} \mathrm{ha}^{-1} \mathrm{P}$ from PM $+40 \mathrm{~kg} \mathrm{ha}^{-1} \mathrm{P}$ from inorganic source. It might be attributed that by enhancing phosphorus accessibility in cotton crop will ultimately enhance the plant growth with higher LAI (Arya and Singh, 2001). Similarly use of integrated sources of phosphorus helped for more expansion of leaves, increased light interception, enhanced plant height, higher CGR, NAR and enhanced the sympodial branches (Mandal and Sinha, 2004). The NAR monitored an increasing trend during the early phases of cotton growth and reduced subsequently. This might be due to higher respiration of leaves in comparison to photosynthesis and reciprocal shadowing of leaves and subsequently reduced mobilization of photo-assimilates from leaves towards bolls, which minimized the NAR. Araei and Mojaddam (2014) documented that organic manures improved the rate of cytokinin and chlorophyll contents in crops, which eventually enhanced the NAR.
Collective use of organic and inorganic P sources improved the cotton growth and productivity as compared with the sole applications (Ghosh et al., 2006). It might be due to the fact that integrative use of $\mathrm{P}$ sources enhanced the accessibility of water holding capacity, soil applied nutrients, stimulation of soil microbial biomass, blockage of $\mathrm{P}$ absorbing sites in the soil and boosted rates of mineralization whereas higher dose of chemical fertilizers alone could probably hurt the roots by salts accumulation around them (Dekissa et al., 2008). This eventually improves the synthesis of number of bolls due to the greater root length and assists in higher $\mathrm{P}$ uptake ensuing in more consumption of assimilates for bolls development. Soil dwelling bacteria have the potential of synthesizing plant hormones which might be liable for enhancement of plant-microbial interaction and for more nutrient uptake thus ultimately enhances the seed cotton and fiber quality parameters by promoting overall crop growth (Saleem et al., 2010). Besides P-solubilization different strains of PSB also produced phytohormones thus improved the crop productivity (Sundaram et al., 2016).

\section{Conclusion}

The organic fertilizers studied provide macro and micronutrients, they can improve cotton productivity without the use of chemical fertilizers. However, the 
combined application of poultry manure and inorganic sources of phosphorus in cotton created with inoculated seeds of strain-1 produced a significantly higher yield with the maximum cost-benefit ratio. It helps to reduce the use of inorganic fertilizers and promotes sustainable agriculture.

\section{References}

AMANULLAH and STEWART, B.A., 2015. Analysis of growth response of cool season cereals "wheat vs. rye" grown in organic and inorganic soils. Emirates Journal of Food and Agriculture, vol. 27, no. 5, pp. 430-440. http://dx.doi.org/10.9755/ ejfa.2015.04.041.

ARAEI, M. and MOJADDAM, M., 2014. The effect of different levels of phosphorus from triple super phosphate chemical fertilizers and biological phosphate fertilizer (fertile 2) on physiological growth parameters of corn (SC704) in AHVAZ weather conditions. International Journal of Plant Animal and Environmental Sciences, vol. 4, pp. 625-632.

ARIF, M., KAREEM, S.H.S., AHMAD, N.S., HUSSAIN, N., YASMEEN, A., ANWAR, A., NAZ, S., IQBAL, J., SHAH, G.A. and ANSAR, M., 2019. Exogenously applied bio-stimulant and synthetic fertilizers to improve the growth, yield and fiber quality of cotton. Sustainability, vol. 11, no. 7, pp. 2171. http://dx.doi. org/10.3390/su11072171.

ARYA, K.C. and SINGH, S.N., 2001. Productivity of maize as influenced by different levels of phosphorus, zinc and irrigation. Indian Journal of Agricultural Sciences, vol. 71, pp. 57-59.

CORDELL, D. and WHITE, S., 2011. Peak phosphorus: clarifying the key issues of a vigorous debate about long-term phosphorus security. Sustainability, vol. 3, no. 10, pp. 2027-2049. http:// dx.doi.org/10.3390/su3102027.

DEKISSA, T., SHORT, I. and ALLEN, J., 2008. Effect of soil amendment with compost on growth and water use efficiency of Amaranth. In: Proceedings of the UCOWR/NIER Annual Conference: International Water Resources: Challenges for the 21st Century and Water Resources Education; 22-24 July 2008; Durham, North Carolina. Carbondale, IL: UCOWR.

GHOSH, P.K., MANNA, M.C., BANDYOPADHYAY, K.K., AJAY., TRIPATHI, A.K., WANJARI, R.H., HATI, K.M., MISRA, A.K., ACHARYA, C.L. and SUBBA RAO, A., 2006. Interspecific interaction and nutrient use in soybean/sorghum intercropping system. Agronomy Journal, vol. 98, no. 4, pp. 1097-1108. http:// dx.doi.org/10.2134/agronj2005.0328.

HUNT, R., 1978. Plant growth analysis. UK: Edward Arnold, pp. 26-38.

JONES, L.A. and KERSEY, J.H., 2002 [viewed 13 January 2020]. Cottonseed article [online]. Memphis: National Cottonseed Products Association. Available from: http://www. cottonseed. com/publication/csobro.Asp

MANDAL, K.J. and SINHA, A.C., 2004. Nutrient management effects on light interception, photosynthesis, growth, dry-matter production and yield of Indian mustard (Brassica juncea L.). Journal Agronomy \& Crop Science, vol. 190, no. 2, pp. 119-129. http://dx.doi.org/10.1046/j.1439-037X.2003.00083.x.

NICO, M., RIBAUDO, C.M., GORI, J.I., CANTORE, M.L. and CURÁ, J.A., 2012. Uptake of phosphate and promotion of vegetative growth in glucose-exuding rice plants (Oryza sativa) inoculated with plant growth-promoting bacteria. Applied Soil
Ecology, vol. 61, pp. 190-195. http://dx.doi.org/10.1016/j. apsoil.2011.10.016.

NOREEN, S., ATHAR, H.U.R. and ASHRAF, M., 2013. Interactive effects of watering regimes and exogenously applied osmoprotectants on earliness indices and leaf area index in cotton (Gossypium hirsutum L.) crop. Pakistan Journal of Botany, vol. 45 , pp. $1873-1881$

PAKISTAN. (2018). Economic survey of Pakistan. Pakistan: Ministry of Food and Agriculture, Federal Bureau of Statistics Islamabad, pp. 15.

SALEEM, M.F., BIAL, M.F., AWAIS, M., SHAHID, M.Q. and ANJUM, S.A., 2010. Effect of nitrogen on seed cotton yield and fiber qualities of cotton (Gossypium hirsutum L.) cultivars. The Journal of Animal and Plant Sciences, vol. 20, pp. 23-27.

SHEN, J.B., LI, C.J., MI, G.H., LI, L., YUAN, L.X., JIANG, R.F. and ZHANG, F.S., 2013. Maximizing root/ rhizosphere efficiency to improve crop productivity and nutrient use efficiency in intensive agriculture of China. Journal of Experimental Botany, vol. 64, no. 5, pp. 1181-1192. http://dx.doi.org/10.1093/jxb/ ers342. PMid:23255279.

SHULI, F., JARWAR, A.H., WANG, X., WANG, L. and MA, Q., 2018. Overview of the cotton in Pakistan and its future prospects. Pakistan Journal of Agricultural Research, vol. 31, no. 4, pp. 396407. http://dx.doi.org/10.17582/journal.pjar/2018/31.4.396.407.

SINGH, P., 2004. Cotton breeding. 2nd ed. New Delhi: Kalyani Publishers, pp. 1-162.

STEEL, R.G.D., TORRIE, J.H. and DEEKEY, D.A., 1997. Principles and procedures of statistics: a biometrical approach. 3rd ed. New York: McGraw Hill Book. pp. 400-428.

SUNDARAM, V.M., KATHIRESAN, D., ESWARAN, S., SANKARALINGAM, S., BALAKAN, B. and HARINATHAN, B., 2016. Phosphate solubilization and phytohormones production by rhizosphere microorganisms. Advances in Agriculture and Biology, vol. 5, pp. 5-13.

SUNDARAM, V.M., KRISHNA, I.K.R. and SREENIVASAN, S., 2002. Handbook of methods of tests for cotton fibers, yarns and fabrics, Part I: Ginning tests, fibre tests, moisture tests, and structural studies. Mumbai: Central Institute for Research on Cotton Technology, pp. 1-19.

VANCE, C.P., UHDE-STONE, C. and ALLAN, D.L., 2003. Phosphorus acquisition and use: critical adaptations by plants for securing a non-renewable resource. The New Phytologist, vol. 157 , no. 3, pp. 423-447. http://dx.doi.org/10.1046/j.14698137.2003.00695.x

WALPOLA, B.C. and YOON, M.H., 2012. Prospectus of phosphate solubilizing microorganisms and phosphorus availability in agricultural soils: a review. African Journal of Microbiological Research, vol. 6, pp. 6600-6605.

WANG, X., TANG, C., GUPPY, C.N. and SALE, P.W.G., 2008. Phosphorus acquisition characteristics of cotton (Gossypium hirsutum L.), wheat (Triticum aestivum L.) and white lupin (Lupinus albus L.) under P deficient conditions. Plant and Soil, vol. 312, no. 1-2, pp. 117-128. http://dx.doi.org/10.1007/s11104-008-9589-1.

WATSON, D.J., 1952. The physiological basis of variation in yield. Advances in Agronomy, vol. 4, pp. 101-145. http://dx.doi. org/10.1016/S0065-2113(08)60307-7.

WU, S.C., CAO, Z.H., LI, Z.G., CHEUNG, K.C. and WONG, M.H., 2005. Effects of biofertilizer containing N-fixer, P and 
$\mathrm{K}$ solubilizers and AM fungi on maize growth: a greenhouse trial. Geoderma, vol. 125, no. 1-2, pp. 155-166. http://dx.doi. org/10.1016/j.geoderma.2004.07.003.

YASMIN, H. and BANO, A., 2011. Isolation and characterization of phosphate solublizing bacteria from rhizosphere soil of weeds of Khewra salt range and Attock. Pakistan Journal of Botany, vol. 43, pp. 1663-1668.

ZHANG, T.G.W., 2001. Present status and prospect on cotton genomic studies. Nanjing, China: Department of Agronomy, Nanjing Agricultural University. 